\title{
Contribuição pioneira do Instituto Evandro Chagas para a saúde ambiental na Amazônia em 25 anos da Seção de Meio Ambiente
}

\section{Pioneering contribution of the Instituto Evandro Chagas's Environmental Section to environmental health in the Amazon over the last 25 years}

Iracina Maura de Jesus ${ }^{1}$, Edilson da Silva Brabo ${ }^{1,+}$, Marcelo de Oliveira Lima ${ }^{1}$, Kleber Raimundo Freitas Faial ${ }^{1}$, Lena Lillian Canto de Sá Moraes', Rosivaldo de Alcântara Mendes', Bruno Santana Carneiro', Vanessa Bandeira da Costa', Volney de Magalhães Câmara², Elisabeth Conceição de Oliveira Santos ${ }^{1}$

'Instituto Evandro Chagas/SVS/MS, Seção de Meio Ambiente, Ananindeua, Pará, Brasil

2 Universidade Federal do Rio de Janeiro, Instituto de Estudos de Saúde Coletiva, Rio de Janeiro, Rio de Janeiro, Brasil

In memoriam

\begin{abstract}
RESUMO
A emergência dos problemas ambientais e suas repercussões na saúde pública, especialmente em populações da Amazônia brasileira, levaram à criação da Seção de Meio Ambiente (SAMAM) do Instituto Evandro Chagas, representando uma inovação institucional, contextualizada no debate mundial e nacional sobre os impactos ambientais de origem antrópica, no início da década de 1990. O programa de pesquisa inicial da SAMAM, dedicado ao estudo de populações expostas ao mercúrio na Amazônia, reuniu grande conteúdo de informações sobre características epidemiológicas, clínicas e laboratoriais de diversos grupos populacionais pesquisados, incluindo ribeirinhos, populações urbana, rural e indígena. Evidenciou-se a necessidade de intensificação da vigilância em saúde dessas populações, devido à persistência e magnitude da exposição observada em alguns locais, associada a condições de vida e morbidade, que podem favorecer o risco de efeitos adversos. Além do programa de mercúrio, a SAMAM também tem desenvolvido estudos sobre outros contaminantes e sobre a qualidade das águas de consumo humano, superficial e subterrânea, para avaliação de indicadores preconizados pela legislação (bactérias, parâmetros físico-químicos, metais e agrotóxicos, dentre outros) e outros possíveis biomarcadores de interesse para a saúde ambiental, como plâncton e vírus. A atuação da SAMAM no Sistema Nacional de Vigilância em Saúde Ambiental é reconhecida em áreas como qualidade da água, metais e agrotóxicos, estando em expansão em outras áreas como cianobactérias e virologia ambiental. A SAMAM também tem contribuído para a capacitação de pessoas do Brasil e do exterior em metodologias analíticas e saúde ambiental.
\end{abstract}

Palavras-chave: Saúde Ambiental; Exposição; Mercúrio; Vigilância.

\section{ABSTRACT}

The emergence of environmental problems and their effects on public health, especially in populations of the Brazilian Amazon, led to the creation of the Environment Section (Seção de Meio Ambiente - SAMAM) of Instituto Evandro Chagas. It represents an institutional innovation, contextualized in the national and world debate on the environmental effects of anthropogenic origin in the early 1990s. SAMAM's initial research program, dedicated to the study of populations exposed to mercury in the Amazon, gathered information on epidemiological, clinical, and laboratory characteristics of riverside, rural, urban, and indigenous populations. The need for intensifying the health surveillance of these populations should be highlighted, due to the persistence and magnitude of the exposure in some places. Such mercury exposure is associated with morbidity and a risk of adverse effects. In addition to the mercury project, SAMAM has also developed studies on other contaminants and on the quality of drinking water, surface water, and groundwater, to evaluate various indicators (e.g., bacteria, physicochemical parameters, metals, pesticides) and other potential biomarkers of interest such as plankton and viruses. SAMAM's performance in the National Environmental Health Surveillance System is recognized in areas such as water quality, metals, and pesticides and is expanding into other areas such as cyanobacteria and environmental virology. SAMAM has also contributed to the training of professionals from Brazil and abroad in analytical methodologies and environmental health.

Keywords: Environmental Health; Exposure; Mercury; Surveillance.

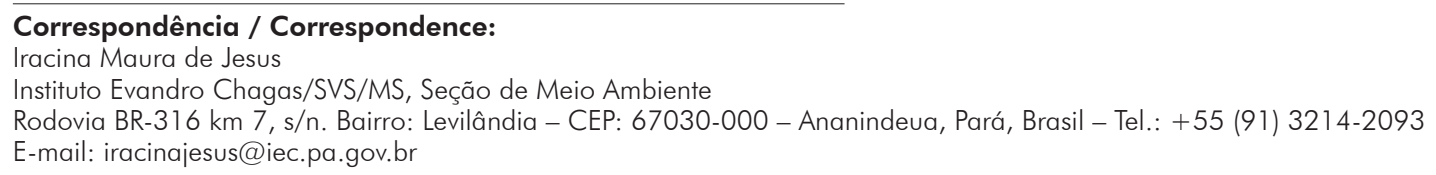




\section{INTRODUÇÃO}

Século XX vivenciou inovações e transformações industriais em larga escala e eventos em nível global, incluindo duas guerras mundiais, os quais geraram grandes fontes de polvição de origem antrópica que, somadas aos eventos naturais, produziram impactos ambientais e catástrofes que atingiram grandes áreas e vitimaram populações. As consequências desses processos são duradouras e se somam aos eventos recorrentes e aos riscos ambientais emergentes. Além disso, os riscos associados à utilização de produtos gerados pela indústria tornaram-se cada vez mais crescentes, como os pesticidas, destinados a beneficiar a agricultura, mas que podem ameaçar a saúde de trabalhadores e consumidores, como observado em estudos de diversos países ${ }^{1,2,3}$. No caso dos pesticidas, tornou-se emblemática a obra de Rachel Carson, em seu livro intitulado "Primavera silenciosa"4, de 1962, sobre a vulnerabilidade da vida silvestre e humana para os danos consequentes ao uso de pesticidas como o diclorodifenil-tricloroetano (DDT) e outros organoclorados e fosforados na agricultura e no domicílio ${ }^{5}$.

As conferências internacionais, promovidas pela Organização das Nações Unidas na segunda metade do século XX, contribuíram para o início da construção de uma consciência global sobre a finitude dos recursos do planeta Terra e para a necessidade de sua conservação e uso sustentável, destacando-se a Conferência sobre - Meio Ambiente Humano, realizada em Estocolmo, Suécia, em 1972, e a Conferência das Nações Unidas para o Meio Ambiente e Desenvolvimento, realizada na Cidade do Rio de Janeiro, em 1992 (ECO-92), que foi sucedida pelas Conferências Rio+10 e Rio+20. Entre a Conferência de Estocolmo e a ECO-92, desenvolveu-se o trabalho da Comissão Mundial de Meio Ambiente e Desenvolvimento, que publicou seu relatório em 1987 (denominado "Nosso futuro comum" ou "Relatório Brundtland"), a qual elaborou a concepção de desenvolvimento sustentável, que seria largamente debatida na ECO-92 e expresso nas premissas da Agenda 21 (assinada por 179 países) ${ }^{6}$ e outros documentos gerados por essas conferências. Tais documentos têm subsidiado a construção de uma política ambiental transversal nos países participantes dos acordos mundiais, visando compromissos de redução de fontes de emissão de polventes, como a recente Convenção de Minamata $^{7}$, em processo de ratificação pelos países signatários, para redução da utilização do mercúrio $(\mathrm{Hg})$ no mundo. Foi nesse cenário mundial e nacional do despertar ambientalista que ocorreu a criação da Seção de Meio Ambiente (SAMAM) do Instituto Evandro Chagas (IEC), em 1992, sobre a qual este artigo aborda aspectos históricos e principais contribuições para a área de saúde ambiental na Amazônia brasileira, em seu legado de 25 anos de existência.

\section{BREVE HISTÓRICO DA CRIAÇÃO DA SAMAM}

A emergência dos problemas ambientais e suas repercussões na saúde pública, especialmente em populações da Amazônia, levaram a pesquisadora da área de Virologia do IEC, Elisabeth Conceição de Oliveira Santos, a procurar o apoio da direção para que o Instituto estendesse sua atuação ao campo da interface da saúde com o ambiente, criando um setor que se ocupasse dessa nova área da saúde pública, em vista do compromisso do IEC com a saúde das populações da Amazônia e seu papel na pesquisa científica nacional e internacional. Assim, com o apoio da direção institucional (sendo, à época, o gestor dr. Jorge Fernando Soares Travassos da Rosa), Elisabeth Santos coordenou um pequeno grupo de pesquisadores (Edvaldo Carlos Brito Loureiro, Iracina Maura de Jesus, Maria de Fátima Lima de Assis e Edilson da Silva Brabo - este último in memoriam) e técnicos (Raimundo Pio Girard Martins, Airton de Jesus da Graça Teixeira, Raimundo Otávio da Paixão e Maria América Guimarães - os dois últimos in memoriam) na criação, em fevereiro de 1992, do Laboratório de Ecologia Humana e Meio Ambiente (LEHMA, de 1992 a 1994), que posteriormente foi denominado Serviço de Ecologia e Meio Ambiente (SEMA, de 1995 a 1996), Coordenação de Ecologia Humana e Meio Ambiente (COEHMA, de 1996 a 2000) e, finalmente em novembro de 2000, constituindo-se na atual SAMAM.

Desde o início, o grupo também contou com parcerias interinstitucionais e de pesquisadores que colaboraram em projetos que possibilitaram a agregação de conhecimento multidisciplinar essenciais para $O$ avanço das pesquisas. Algumas dessas parcerias permanecem até os dias atuais, como é o caso do Instituto de Estudos de Saúde Coletiva (IESC) da Universidade Federal do Rio de Janeiro (UFRJ), por meio do dr. Volney de Magalhães Câmara, parceiro em muitos projetos da SAMAM, tanto na área de pesquisas em populações expostas ao $\mathrm{Hg}$, quanto na área de capacitação de recursos humanos em saúde ambiental. A criação da SAMAM, além de fruto da atenção e dos ideais da dra. Elisabeth Santos pelas questões ambientais e suas repercussões na saúde e qualidade de vida na Amazônia, representou, sobretudo, um novo universo de atuação para o IEC em pesquisa e investigação de campo na área ambiental. Além disso, proporcionou a ampliação da capacidade de resposta à demanda de vigilância em saúde nessa nova área denominada Saúde Ambiental, que ainda estava sendo delineada de forma incipiente no Brasil durante a década de 1990, com base nos debates e definições internacionais e nacionais que estavam em curso sobre o tema.

Previamente à criação da SAMAM, destacaram-se dois acontecimentos que proporcionaram subsídios para essa decisão institucional. No ano de 1991 (30 de setembro a 4 de outubro), foi realizado, pela Secretaria de Estado de Indústria, Comércio e Mineração (SEICOM), o treinamento para integração e nivelamento da equipe executora dos estudos dos impactos ambientais decorrentes do extrativismo mineral no Tapajós, Canga-Tapajós, do qual participaram os representantes do IEC e da Fundação Nacional de Saúde (FNS, atual Funasa), Elisabeth Santos, Edvaldo Loureiro e Iracina de Jesus. Esse treinamento reuniu 
pesquisadores e técnicos de instituições governamentais para a colaboração no referido projeto. Tal evento foi de grande importância para a aproximação dos pesquisadores com a temática da garimpagem de ouro e atores científicos e governamentais envolvidos com a mineração na bacia do rio Tapajós, região que viria a ser um dos principais alvos de estudo da SAMAM nas próximas décadas, em relação à exposição ao $\mathrm{Hg}$.

programa Canga-Tapajós, elaborado em 1989 pelo Governo do Estado do Pará, por meio da SEICOM, visou conhecer, em profundidade e magnitude, a garimpagem de ouro na bacia do rio Tapajós e planejar ações integradas para melhoria da produtividade, porém com redução de danos às populações e ao ambiente. $\bigcirc$ programa se ocupou do diagnóstico econômico e social de áreas de garimpo, melhorias tecnológicas na extração de ouro e na recuperação do $\mathrm{Hg}$, além de alternativas econômicas passíveis de associação à mineração e ao levantamento de informações para a promoção da consciência ambiental da população ${ }^{8}$. Integrado ao programa, foi desenvolvido, a partir de 1991, o projeto "Estudos dos impactos ambientais decorrentes do extrativismo mineral", o qual teve, como primeira atividade, o treinamento de integração e nivelamento dos participantes das instituições envolvidas, conforme citado anteriormente.

Nesse projeto, a SAMAM contribuiu na avaliação da contaminação de peixes por $\mathrm{Hg}$ na área do estudo na região do Tapajós, fazendo parte da equipe de coleta de campo, em colaboração com a SEICOM e com o Departamento Nacional de Produção Mineral (DNPM) do Ministério de Minas e Energia (MME), sendo que a disponibilidade de dados sobre a concentração de $\mathrm{Hg}$ em peixes dessa região era considerada muito limitada no início da década de 1990. As análises de $\mathrm{Hg}$ foram realizadas no laboratório do Departamento de Química da Pontifícia Universidade Católica do Rio de Janeiro, pois, até então, o IEC não possuía laboratório de $\mathrm{Hg}$.

Ainda no segundo semestre de 1991, a equipe do IEC e FNS que participou do treinamento, acompanhada pela geóloga da SEICOM, Rita Rodrigues, realizou viagem de campo à Cidade de Itaituba, Estado do Pará, e a dois garimpos da região, Cuiu-Cuiu e Creporizão, a fim de conhecer a realidade local e levantar informações para o desenvolvimento de futuros projetos em área de garimpo. Os impactos na paisagem, as insalubres condições de trabalho, o processo de queima do amálgama ouro-mercúrio, os vilarejos ou corrutelas em torno dos garimpos com a presença inclusive de crianças e idosos, moradias precárias, falta de saneamento, consumo de água de poço ou cisterna sem tratamento, relatos de violência, ocorrência de malária, hepatite e outras endemias, ausência de serviços de saúde, exceto o de controle de malária, vendas de medicamentos, ouro como moeda local, desconhecimento dos riscos do mercúrio, foram algumas das observações de campo que chamaram a atenção da equipe. Essa experiência inicial foi de grande importância para o planejamento da primeira expedição com coleta de campo, que ocorreria no ano seguinte em outra área garimpeira do Município de Itaituba, também com condições logísticas difíceis e acesso apenas aéreo.

\section{PROJETOS DE IMPORTÂNCIA HISTÓRICA PARA A SAMAM}

Com a criação do LEHMA, o primeiro programa de trabalho estabelecido para ser desenvolvido em um período de 10 anos objetivou investigar diferentes populações e ambientes epidemiológicos submetidos à polvição ambiental por $\mathrm{Hg}$. Esse programa originou - grupo de pesquisa mais antigo da SAMAM, denominado "Mercúrio em populações e no ambiente amazônico". No primeiro semestre de 1992, a convite do dr. Alexandre Pessoa da Silva, coordenador técnico do "Projeto Itaituba: programa de desenvolvimento de tecnologia ambiental", desenvolvido pelo Centro de Tecnologia Mineral (CETEM) do então Ministério da Ciência e Tecnologia, hoje Ministério da Ciência, Tecnologia, Inovações e Comunicações (MCTIC)9 , o LEHMA desenvolveu uma proposta de estudo de saúde humana para a área do garimpo do Rato, a qual foi executada em setembro de 1992, constituindo-se na primeira expedição de campo com a realização de inquérito epidemiológico, avaliação clínica e coleta de material biológico na área de saúde ambiental do IEC (Figura 1). Esse estudo também incluiu a avaliação da qualidade da água para consumo humano e água superficial no garimpo do Rato ${ }^{10}$. A equipe de pesquisa do LEHMA/IEC já contava com a presença de um geólogo, Edilson Brabo, que havia se agregado à equipe em junho de 1992, além de outros pesquisadores envolvidos nesse projeto, como Izabel Rodrigues (Seção de Parasitologia do IEC) e os médicos Fernando Branches (cardiologista de Santarém) e Rita Uchôa da Silva (FNS/IEC) e do também geólogo Artur Fernando Silva Mascarenhas (SEICOM). Nesse estudo, as determinações de $\mathrm{Hg}$ total já foram realizadas no Laboratório de Toxicologia do IEC e também no Laboratório de Radioisótopos do Instituto de Biofísica Carlos Chagas Filho da UFRJ.

A partir dessa exitosa experiência de estudos de campo, sucederam outras que ampliaram a diversidade populacional pesquisada. Para citar aquelas de maior impacto na história da SAMAM, destaca-se o desenvolvimento dos estudos do Projeto Mercúrio, coordenado pelo dr. David Cleary, do Centre of Latin American Studies, University of Cambridge, Reino Unido, no período 1994 a 1997, financiado pela União Europeia"1. $\bigcirc$ projeto objetivou a avaliação dos impactos do $\mathrm{Hg}$ no ambiente, na biota ${ }^{12}$ e na saúde de populações expostas de forma ocupacional e ambiental ${ }^{13}$ na bacia do Tapajós, com proposição de alternativas tecnológicas para diminuição dos impactos negativos da mineração. No Projeto Mercúrio, o LEHMA/IEC coordenou os estudos de saúde ${ }^{14,15}$ e, em diversas oportunidades, a equipe de pesquisa interagiu com outros grupos multidisciplinares do projeto em trabalhos de campo. Foram pesquisadas quatro 
comunidades ribeirinhas (três na bacia do Tapajós e uma no rio Amazonas) e dois grupos de trabalhadores das lojas de comercialização de ouro nas Cidades de Santarém e Itaituba ${ }^{16}$

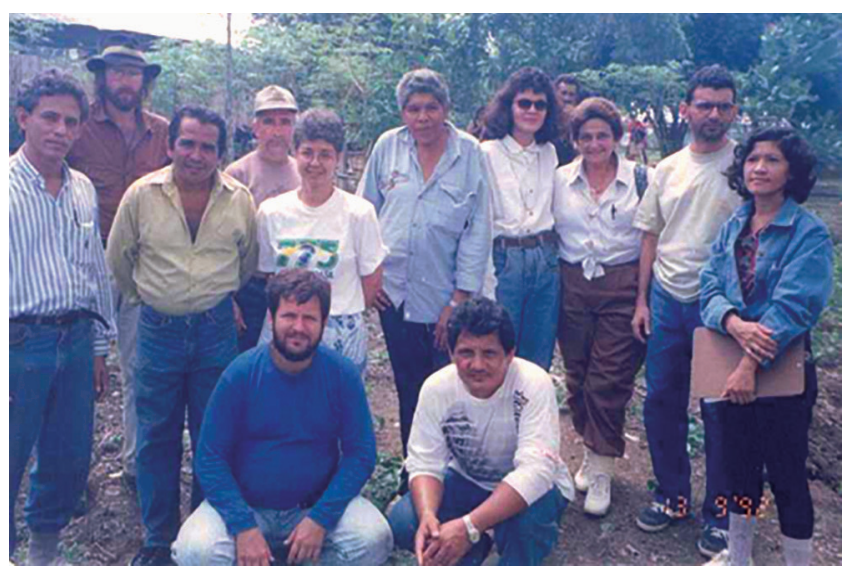

$\mathrm{Na}$ frente, da direita para a esquerda: Airton de Jesus da Graça Teixeira e Artur Fernando Silva Mascarenhas. Em pé, da direita para a esquerda: Iracina Maura de Jesus, Edilson da Silva Brabo, Elisabeth Conceição de Oliveira Santos, Rita Uchoa da Silva, Raimundo Otávio da Paixão, Izabel Carvalho Rodrigues, Fernando Branches, Edvaldo Carlos Brito Loureiro, Raimundo Pio Girard Martins e Bernhard Gregor Peregovich.

Figura 1 - Equipe de campo da SAMAM/IEC, em parceria com o CETEM/MCTIC e SEICOM, no garimpo do Rato, Bacia do Tapajós, Itaituba, Estado do Pará, Brasil, em setembro de 1992, coordenada pela pesquisadora Elisabeth Santos

Na segunda metade da década de 1990, foram desenvolvidos estudos em outras comunidades ribeirinhas dos rios Tapajós e Amazonas em projetos financiados por agências de fomentos estaduais e nacionais. No final dessa década, foi desenvolvido ainda um projeto de grande importância para o campo da saúde ambiental na Região Amazônica, referente à pesquisa da ocorrência do $\mathrm{Hg}$ no ambiente ${ }^{17} \mathrm{e}$ exposição populacional no Estado do Acre $^{18}$ (bacia do rio Acre e Cidade de Rio Branco). Tendo em vista que esse Estado não possuía fonte antrópica de $\mathrm{Hg}$ conhecida e havendo relatos de indivíduos expostos ao $\mathrm{Hg}$, originou-se, por parte de órgãos municipais, estaduais e federais, incluindo o Ministério Público e o Ministério da Saúde (MS), essa demanda de pesquisa atendida pelo IEC.

No começo da década de 2000, a SAMAM desenvolveu um grande projeto para a avaliação da exposição ao arsênio na população da Comunidade Elesbão, Município de Santana, Estado do Amapá. Nesse local, havia grandes quantidades de resíduos do processo de pelotização do manganês, extraído da mina de Serra do Navio, com liberação de arsênio para o ambiente, que poderia representar risco à saúde da população. Por esse motivo, o MS demandou ao IEC a pesquisa em materiais ambientais, bem como o estudo populacional em 2.048 indivíduos residentes na área ${ }^{19}$. Ainda em 2000, a SAMAM iniciou o projeto denominado "Mercúrio em recém-nascidos e mães da Cidade de Itaituba, Estado do Pará", que visou avaliar os níveis de exposição ao Hg no nascimento e durante os primeiros anos de vida. $O$ projeto se estendeu até 2010 e acompanhou mães e suas crianças nascidas em hospitais de Itaituba, com seguimento periódico das crianças residentes no Município e localidades próximas $^{20,21}$.

Ainda nessa década, a SAMAM voltou a desenvolver pesquisas em populações garimpeiras, coordenando - estudo de saúde nos garimpos de São Chico e Creporizinho, na bacia do Tapajós, como parte do projeto internacional "Mercúrio global - remoção de barreiras para a introdução de tecnologias limpas de mineração artesanal e extração de ouro"22, coordenado no Brasil pelo dr. Roberto Villas-Bôas (CETEM/MCTIC) e financiado pela Organização das Nações Unidas para - Desenvolvimento Industrial (UNIDO). Também nessa década, prosseguiram os estudos de saúde humana e ambiental em municípios do Acre.

Na segunda metade da década de 2000, a SAMAM iniciou o programa de monitoramento e controle em saúde e meio ambiente em áreas industriais e portuárias dos Municípios de Abaetetuba e Barcarena, Estado do Pará. $\bigcirc$ programa incluiu projetos que objetivaram a avaliação da saúde humana, exposição a metais e danos aos ecossistemas aquáticos, a partir do lançamento de polventes nos corpos hídricos da região, e foi financiado com recursos de um Termo de Ajuste de Conduta (TAC) IRCC/MPE-PA/FIDESA/IEC. Já na década de 2010, a SAMAM passou a desenvolver - monitoramento da qualidade da água (consumo, superficial e subterrânea) e avaliação de biomarcadores em ecossistemas aquáticos de áreas portuárias da região metropolitana de Belém e Município de Barcarena. Esses estudos ambientais têm capacitado o IEC para respostas rápidas na avaliação de impactos no ecossistema em casos de acidentes com resíduos industriais e de mineração, bem como de outra natureza, como o naufrágio de carga viva de grandes proporções ${ }^{23}$ que atingiu o Rio Pará em 2015.

\section{CONTRIBUIÇÕES DOS ESTUDOS DE SAÚDE HUMANA EM RELAÇÃO AO MERCÚRIO}

programa de pesquisa inicial da SAMAM, dedicado ao estudo de populações expostas ao $\mathrm{Hg}$ na Amazônia, reuniu um vasto conteúdo de informações quanto às características epidemiológicas, clínicas e laboratoriais de diversos grupos populacionais, incluindo ribeirinhos, populações urbana e rural e indígenas. Desde os primeiros estudos, a metodologia empregada envolvia uma abordagem integradora da epidemiologia, clínica e laboratório, a fim de contextualizar a avaliação das condições de vida e saúde dos participantes. Outro fato importante é que, mesmo antes do estabelecimento das resoluções brasileiras sobre pesquisas com seres humanos, a SAMAM já utilizava termo de consentimento para os participantes dos estudos, atendendo a princípios éticos internacionais. Em relação ao tipo de exposição ao $\mathrm{Hg}$, foram pesquisados grupos expostos ao vapor de $\mathrm{Hg}$ ou Hg metálico (exposição ocupacional de trabalhadores e de pessoas residentes próximas a fontes de emissão 
de vapor de $\mathrm{Hg}$ ) e grupos expostos ambientalmente pelo consumo de peixes contendo a substância. Os trabalhadores de garimpo apresentaram $\mathrm{Hg}$ em urina com teores variáveis, sendo, em alguns casos, bastante elevados. No entanto, os estudos em trabalhadores de estabelecimentos de compra de ouro ${ }^{16}$, na década de 1990, mostraram níveis de $\mathrm{Hg}$ na urina com média variando de 9,5 a 81,1 $\mu \mathrm{g} \cdot \mathrm{L}^{-1}$, indicando situações de maior exposição em relação aos garimpos na mesma década $^{10}$ (que apresentaram média de 6,4 $\mu \mathrm{g} \cdot \mathrm{L}^{-1}$ ) e na década seguinte ${ }^{22}$ (média de $\mathrm{Hg}$ em urina de 13,75 e 17,37 $\mu \mathrm{g} \cdot \mathrm{L}^{-1}$ em dois garimpos de ltaituba).

Os estudos indicaram a ocorrência de elevada exposição ao $\mathrm{Hg}$ em algumas comunidades da bacia do rio Tapajós (média variando de 11,75 a 19,91 $\mu \mathrm{g} \cdot \mathrm{g}^{-1}$ em cabelo) ${ }^{14}$, com persistência da exposição. Esses teores mostraram-se maiores nesses locais quando comparados com áreas mais afastadas, no rio Amazonas ${ }^{15,24}$ (média de $\mathrm{Hg}$ de 4,3 $\mu \mathrm{g} \cdot \mathrm{g}^{-1}$ ), e em sub-bacias do Estado do Acre, com média de $\mathrm{Hg}$ em cabelo de 2,41 $\mu \mathrm{g} \mathrm{g}^{-1}$ em Rio Branco ${ }^{18}$, na bacia do rio Acre, e média de 3,99 $\mu \mathrm{g}^{-\mathrm{g}^{-1}}$ no agrupamento de três cidades da bacia do rio Juruá ${ }^{25}$. Em algumas cidades do Acre, incluindo Rio Branco, uma pequena parte da população apresentava níveis moderados ou elevados de exposição, segundo referências internacionais ${ }^{26}$. Em áreas de conservação ambiental, como florestas nacionais, também se verificou um nível de exposição intermediário entre o que foi observado na bacia do Tapajós e nas áreas mais afastadas tidas como áreas não diretamente impactadas pelo $\mathrm{Hg}^{15}$. Os recém-nascidos pesquisados em Itaituba apresentaram teores de $\mathrm{Hg}$ superiores aos níveis apresentados por suas mães (média de 16,68 $\mu \mathrm{g} \cdot \mathrm{L}^{-1}$ em sangue de cordão umbilical e de 11,53 $\mu \mathrm{g} \cdot \mathrm{L}^{-1}$ em sangue materno), sugerindo exposição fetal e transferência de carga de $\mathrm{Hg}$ por via placentária ${ }^{20}$, havendo diminuição do teor de $\mathrm{Hg}$ nos primeiros quatro anos de vida e tendência ao aumento nos anos seguintes $^{21}$. Os resultados dos estudos evidenciaram a necessidade de intensificação de vigilância em saúde das populações expostas ao $\mathrm{Hg}$, devido aos níveis de exposição encontrados ${ }^{14,27}$ e às condições de vida e morbidade prevalente, que podem favorecer os riscos de efeitos adversos ${ }^{28,29}$. A avaliação dos níveis de $\mathrm{Hg}$ em pescado nas localidades pesquisadas, sobretudo em peixes carnívoros, tem demonstrado consonância com a exposição verificada nas populações ${ }^{15}$. Os estudos prosseguem com o monitoramento de grupos populacionais com exposição elevada ou de maior vulnerabilidade e com a utilização de novos biomarcadores para avaliação de impactos precoces em sistemas orgânicos.

\section{CONTRIBUIÇÕES DOS ESTUDOS AMBIENTAIS E BIOLÓGICOS E AÇÕES DE VIGILÂNCIA}

\section{CONTAMINANTES ORGÂNICOS NA AMAZÔNIA}

A contaminação do ambiente amazônico por agrotóxicos ou pesticidas pode ser descrita em duas etapas. A primeira relaciona-se ao uso indiscriminado de pesticidas no combate a endemias, como a malária, e à abertura de novas fronteiras na região, como a construção da Rodovia Transamazônica. Essas ações resultaram em um lançamento de grandes quantidades desses produtos na região, com possíveis danos ao equilíbrio ecológico, como é o caso do DDT, um produto altamente tóxico, persistente no ambiente e que tem a capacidade de bioacumulação na cadeia alimentar. $\bigcirc$ DDT foi utilizado em toda a Região Amazônica e contaminou praticamente todos os compartimentos ambientais, como também a biota aquática $^{30,31}$. Os indivíduos diretamente expostos, como os agentes de saúde que aplicavam o produto no intra e extradomicílio, podem ter sido contaminados devido à exposição continuada durante ações de combate à malária $^{32}$.

A segunda etapa de contaminação é recente e relaciona-se com a fronteira agrícola naquela região. $\bigcirc$ cultivo de monoculturas, como a soja e o dendêe ${ }^{33}$, a produção de arroz na ilha do Marajó e de laranja na região nordeste do Estado do Pará, que utilizam grandes quantidades de agrotóxicos, como o glifosato, estão degradando grandes áreas da floresta e colocando em risco as populações tradicionais e suas comunidades, como os quilombolas e os indígenas.

O IEC, por meio da SAMAM, foi inicialmente designado pelo MS para investigar e analisar a exposição humana a pesticidas, com a determinação de DDT em soro sanguíneo dos agentes de saúde da Funasa. Atualmente, a SAMAM tem recebido demandas dessa natureza de diversos Estados da Amazônia. Além disso, tem realizado a determinação de colinesterase sérica e eritrocitária em agentes de saúde que atuam no controle de endemias. Na última década, em função dos graves problemas ambientais que os agrotóxicos têm gerado em várias regiões do País, a Seção tornou-se referência para o Sistema Nacional de Vigilância em Saúde Ambiental (SINVSA), atuando no Programa Nacional de Monitoramento de Agrotóxicos em Água para Consumo Humano (VIGIAGUA), gerido pela Coordenação Geral de Vigilância em Saúde Ambiental (CGVAM) da Secretaria de Vigilância em Saúde (SVS) do MS, bem como na avaliação de solos contaminados, no âmbito do Programa de Vigilância de Populações Expostas a Agentes Químicos (VIGIPEQ/CGVAM/SVS/MS).

\section{BACTÉRIAS E VÍRUS NO AMBIENTE}

A área de pesquisa em Microbiologia Ambiental foi inicialmente implantada, na atual SAMAM, para o desenvolvimento de estudos voltados à avaliação bacteriológica da qualidade da água, sobretudo aquela utilizada para consumo humano e sua relação com as doenças de veiculação hídrica, ainda em 1992. Com o passar dos anos, esses estudos evoluíram do isolamento, identificação e quantificação de enterobactérias utilizando métodos de cultivo em meios de enriquecimento e aqueles seletivos e indicadores, para pesquisa em nível molecular de diferentes 
espécies e gêneros de bactérias, inclusive pesquisa de genes de virulência e resistência aos antimicrobianos e metais.

Uma importante coleção de isolados bacterianos das famílias Enterobacteriaceae, Vibrionaceae e Aeromonadaceae foi constituída no Laboratório de Microbiologia Ambiental (LMA), de modo que permitiu também a realização de estudos de genética populacional de bactérias, com a identificação de importante marcador molecular entre cepas patogênicas que circularam na Amazônia em epidemia causada por bactéria ${ }^{34}$. Isso possibilitou a elucidação, a nível molecular, dos mecanismos de fermentação da sacarose em cepas amazônidas de Vibrio cholerae Ol da sétima pandemia, que são sacarose negativas, diferindo do padrão de cepas epidêmicas que são sacarose positivas ${ }^{35}$. Houve, ainda, o sequenciamento completo do primeiro genoma bacteriano pelo IEC, um isolado paraense de Vibrio cholerae $\mathrm{Ol}$ da sétima pandemia de cólera, o que permitiu a elucidação de suas principais características genéticas ${ }^{36}$, além de outro isolado de Vibrio cholerae NAG ambiental isolado pelo $\mathrm{LMA}^{37}$.

Outra linha de estudos e investigações mais recente inclui a detecção e caracterização de vírus entéricos em diferentes ecossistemas aquáticos ${ }^{38}$. Nesse contexto, o vírus da hepatite $A$ tem sido amplamente detectado na região metropolitana de Belém, incluindo águas destinadas ao consumo humano, tratadas e não tratadas, águas de diferentes praias, igarapés e rios, além de corpos hídricos receptores de efluentes de esgotos sanitário, doméstico e industrial não tratados, - que apresenta forte relação com os achados epidemiológicos para hepatite $A$ na região. Tem sido observado, tanto no âmbito das pesquisas quanto na vigilância, que predomina regionalmente o genótipo I do vírus da hepatite A 1, com a cocirculação dos subgenótipos IA e IB. No contexto da vigilância, no período de 2012 até o presente momento, o IEC tem colaborado na investigação de 41 surtos de hepatite A ocorridos em diferentes Estados do Brasil, dentre os quais, 13 tiveram suas fontes de contaminação identificadas.

A participação efetiva na rede de vigilância em saúde ambiental, mais especificamente na área de virologia ambiental, ocorre na perspectiva da recomendação da detecção de vírus em matrizes aquáticas, como base laboratorial para a vigilância epidemiológica das doenças virais de veiculação hídrica; entretanto, não há, atualmente, em nível mundial, uma metodologia padronizada para os diferentes tipos e complexidade de águas existentes, - que representa importante desafio no âmbito do SINVSA. Esforços têm sido realizados no sentido do desenvolvimento de métodos simples, rápidos, reprodutíveis, com baixo custo e recuperação de uma grande variedade de tipos virais para aplicação em monitoramento da qualidade da água em nível nacional. Entretanto, a pesquisa de vírus entéricos em amostras ambientais encontra-se, atualmente, restrita aos grandes laboratórios de pesquisa do País, entre eles - LMA/SAMAM/IEC.

\section{PLÂNCTON E CIANOBACTÉRIAS}

A área voltada ao estudo das comunidades planctônicas foi desenvolvida inicialmente no âmbito do LMA/SAMAM/IEC e organizou-se como Laboratório de Biologia Ambiental em janeiro de 2013. Os estudos iniciais estavam relacionados ao papel dos copépodes da comunidade planctônica como hospedeiros de Vibrio cholerae. A partir de 2000, por meio de parcerias interinstitucionais, foram realizadas investigações sobre florações de cianobactérias e detecção de cianotoxinas em ecossistemas amazônicos, que fomentaram a aprovação do projeto intitulado "Estudos sobre o processo de eutrofização do rio Iriri" junto ao Fundo Estadual de Ciência e Tecnologia da Secretaria Executiva de Ciência, Tecnologia e Meio Ambiente do Governo do Estado do Pará (Edital 2003), o qual se propôs realizar um estudo piloto sobre o processo de eutrofização do rio Iriri, avaliando, entre outros fatores, a composição de cianobactérias e os teores de cianotoxinas naquele ecossistema.

Nos anos de 2006 e 2007, foi realizada a investigação da ocorrência de um bloom de cianobactérias tóxicas na margem direita do rio Tapaiós, no Município de Santarém, Estado do Pará, sendo os resultados publicados na Revista Pan-Amazônica de Saúde ${ }^{39}$. A partir de 2008, foram desenvolvidos projetos sobre a utilização de plâncton e cianobactérias como biomarcadores ambientais na avaliação de áreas monitoradas ${ }^{40}$, no âmbito do Programa Barcarena e em outras áreas, tendo sido firmadas parcerias com outros grupos de pesquisa, estendendo-se também as atividades para a área de macroinvertebrados bentônicos.

A SAMAM desenvolve investigações relacionadas a cianobactérias e cianotoxinas no âmbito do SINVSA desde o ano de 2012, por meio do envio de profissionais para coleta e análises de amostras em laboratório. Essas demandas são provenientes de diversas regiões do Brasil, como ocorrido na avaliação dos microorganismos fotossintetizantes e da presença de cianotoxinas no Ribeirão Taquaruçu Grande em Palmas, Estado de Tocantins; e na avaliação de cianobactérias e cianotoxinas em amostras dos lagos João Godofredo e da Viúva, no Estado de Mato Grosso. Essa área da SAMAM está consolidando o seu papel no SINVSA, no sentido de se tornar referência para as análises de cianobactérias e cianotoxinas e para a capacitação de profissionais de outros órgãos de vigilância no Brasil, por treinamentos de coletas e/ou análises desses agentes em ambientes aquáticos. Além disso, tem realizado a investigação de surtos, danos e/ou impactos ambientais em diversos municípios da Região Amazônica, em atenção à vigilância e às demandas do Ministério Público. 


\section{BIOINDICADORES E BIOMARCADORES}

A SAMAM, em seus estudos acerca de possíveis rotas de exposição ambiental a contaminantes na Amazônia, tem, historicamente, utilizado bioindicadores de exposição como peixes ${ }^{15,24}$ e, mais recentemente, camarões, caranguejos, botos e tartarugas da Amazônia, a partir dos quais são dosados metais (biomarcadores) em diversos tecidos, como músculo, fígado, entre outros. A partir desses, evolviu o interesse pela quantificação de biomarcadores bioquímicos usados para avaliar, por exemplo, o efeito sobre os organismos aquáticos da contaminação dos corpos hídricos, como vem sendo desenvolvido pelo Laboratório de Toxicologia no projeto de saúde e meio ambiente na bacia hidrográfica do rio Aurá, Estado do Pará, local onde são lançados continuamente - chorume do Lixão do Aurá. Contudo, outros biomarcadores bioquímicos, endócrinos e imunológicos têm sido utilizados em projetos em desenvolvimento no Laboratório de Biologia Humana, para avaliar os efeitos subclínicos da exposição humana a polventes e como auxílio no diagnóstico diferencial em avaliações clínicas de indivíduos expostos.

\section{PARCERIA COM A JICA}

histórico de cooperação do IEC com a Agência de Cooperação Internacional do Japão (JICA) já ultrapassa duas décadas de parceria. Na primeira metade da década de 1990, o IEC participou, junto com o DNPM/MME e com o CETEM/MCTIC, da primeira cooperação, por meio da qual o IEC e os demais parceiros brasileiros receberam doações de equipamentos de análise de $\mathrm{Hg}$ e metilmercúrio. Esse foi o início da transferência de conhecimento e tecnologia que permitiu, ao IEC, dispor de uma equipe treinada em uma metodologia de alta qualidade para a análise laboratorial das formas de $\mathrm{Hg}$, agente químico de importância para a vigilância da saúde das populações da Amazônia, devido à ocorrência da exposição ambiental e ocupacional. A Instituição japonesa envolvida na cooperação foi o Instituto Nacional para a Doença de Minamata (NIMD), sendo a equipe liderada pelo dr. Hirokatsu Akagi, o qual realizou treinamento de pesquisadores da SAMAM no Japão e no próprio IEC.

Entre os anos de 2007 a 2011, houve uma nova cooperação entre o IEC, a Universidade Federal do Pará (UFPA) e a JICA, NIMD e o Laboratório Internacional de Mercúrio (instituições japonesas). Por meio dessa cooperação, foram realizados novos treinamentos em metodologias analíticas, treinamentos laboratoriais e epidemiológicos em Minamata, Japão, e treinamento em investigação epidemiológica e clínica em estudos na bacia do rio Tapajós, Estado do Pará. Houve ainda a doação de novos equipamentos de análise de $\mathrm{Hg}$ para as instituições brasileiras, atualizando as metodologias analíticas. Ao final dessa cooperação, o IEC realizou o I Simpósio sobre Impactos do Mercúrio no Ambiente e na Saúde Humana, realizado no IEC, em Ananindeua, em julho de 2010.
Motivada pela proposta de retomada dos estudos de $\mathrm{Hg}$ no Estado do Acre (iniciativa da dra. Elisabeth Santos, na época, diretora do (EC), uma nova cooperação do IEC foi efetivada, no período de 2012 a 2014, com a JICA, NIMD, Laboratório Internacional de Mercúrio e Prefeitura da Cidade de Minamata, para o fortalecimento da vigilância da exposição ao $\mathrm{Hg}$ no Acre. No âmbito dessa cooperação, houve a capacitação de técnicos do IEC e daquele Estado em Minamata. O IEC realizou ainda estudos sobre a exposição ao $\mathrm{Hg}$ nas Cidades de Manoel Urbano e Sena Madureira, áreas com indícios de exposição ao $\mathrm{Hg}$ em estudos preliminares da década anterior. Nesse período, foi realizado, no Acre, o I Ciclo de Palestras de Saúde Ambiental: Prevenindo os Riscos do Mercúrio, com o desenvolvimento de oficinas pedagógicas em escolas locais sobre educação ambiental com ênfase na prevenção da exposição ao $\mathrm{Hg}$. Os resultados foram apresentados durante o II Simpósio sobre Impactos do Mercúrio no Ambiente e na Saúde Humana, realizado em Belém, em março de 2014, com a participação de autoridades e técnicos das instituições de saúde e ambiente do Acre, além de convidados nacionais e das instituições do Japão.

Devido à consolidação da capacidade técnicocientífica e tecnológica na SAMAM, em relação às pesquisas e ações sobre o $\mathrm{Hg}$ na Amazônia, foi assinada, para o período 2012-2015, uma nova cooperação entre IEC, JICA e Agência Brasileira de Cooperação/Ministério das Relações Exteriores. Dessa vez, objetivou-se a capacitação de técnicos dos países da Pan-Amazônia em análises de $\mathrm{Hg}$ total e metilmercúrio e em epidemiologia e saúde ambiental, com ênfase na vigilância de populações expostas ao $\mathrm{Hg}$ nesses países. Essa cooperação ocorreu na modalidade denominada Programa de Treinamento para Terceiros Países, no qual o Brasil e o Japão proporcionaram capacitação para outros países. Por meio desse evento sediado no IEC, foram capacitados 39 técnicos de sete países (Bolívia, Colômbia, Equador, Guatemala, Peru, Suriname e Venezuela). Foram realizadas três edições anuais dos cursos internacionais, sendo três módulos de Análise de Mercúrio Total e Metilmercúrio e dois módulos de Epidemiologia e Saúde Ambiental. O objetivo principal da cooperação foi promover o estabelecimento de uma rede pan-amazônica de monitoramento da exposição ao $\mathrm{Hg}$, contribuindo para a vigilância da saúde das populações. Em outubro de 2015, foi realizada a I Reunião Internacional para Fortalecimento da Rede de Vigilância Ambiental do Mercúrio na América Latina, incluindo o workshop sobre Proposta de Formação da Rede de Vigilância Ambiental do Mercúrio na América Latina e o III Simpósio Internacional sobre os Impactos do Mercúrio no Ambiente e na Saúde Humana, com a participação dos países integrantes da cooperação; e, durante os eventos, foi debatido a formação dessa rede de monitoramento do $\mathrm{Hg}$ na região.

Embora o IEC disponha, atualmente, de um parque analítico com equipamentos diversificados para a execução de análises de $\mathrm{Hg}$ em diversas matrizes, as 
principais metodologias analíticas, adotadas até o presente, para a análise e especiação de $\mathrm{Hg}$, são os métodos estabelecidos e atualizados ao longo das diversas cooperações entre o IEC e a JICA. No sentido de ampliar a capacidade analítica institucional e de treinamento, o Instituto também tem adquirido outros equipamentos dedicados às mesmas metodologias (espectrometria de absorção atômica por vapor frio para $\mathrm{Hg}$ total; e cromatografia gasosa, com detector de captura de elétron, para metilmercúrio, respectivamente), segundo o método Akagi ${ }^{41}$. $\bigcirc$ compartilhamento de experiências dos estudos epidemiológicos nos cursos, treinamentos e projetos em cooperação, possibilitou, à equipe da SAMAM, avanços técnicos e científicos significativos no desenvolvimento de pesquisas e apoio à vigilância em saúde em populações expostas ao Hg na Amazônia.

\section{CONSIDERAÇÕES FINAIS}

A SAMAM/IEC apresenta uma grande estrutura, com cinco laboratórios (Toxicologia; Microbiologia Ambiental; Biologia Humana; Biologia Ambiental; e Citogenética e Cultura de Tecidos) e cinco setores, com diversas atividades que não foram contempladas o suficiente neste artigo, o qual se propôs a destacar apenas os principais aspectos de atuação em saúde ambiental, dessa não tão longa, porém intensa, história de importante contribuição para a pesquisa e vigilância em saúde ambiental na Região Amazônica e no Brasil. A SAMAM tem, a sua frente, o grande desafio de continuar inovando nas pesquisas e desenvolvendo novas metodologias analíticas ao mesmo tempo em que fortalece o seu papel regional, nacional e internacional nos campos em que já possui excelência. Sua atuação no SINVSA é reconhecida em áreas como qualidade da água, metais e agrotóxicos, estando em expansão em outras, como cianobactérias e virologia ambiental. A SAMAM também desenvolve estudos em áreas sob impactos ambientais de contaminantes químicos, como metais e compostos orgânicos, analisando matrizes ambientais e biológicas por diversas metodologias analíticas, incluindo técnicas multielementares. Também tem contribuído, desde a sua origem, para a formação e capacitação de pessoas por meio de cursos, treinamentos, estágios e apoio ao desenvolvimento de trabalhos de conclusão de curso, mestrado e doutorado, no sentido de contribuir para o aumento de massa crítica para a Amazônia e o País.

Devido ao seu campo transversal de atuação, que promove a interação da diversidade de disciplinas e a utilização de ferramentas metodológicas múltiplas para abordagem de um mesmo problema, a SAMAM possui uma metodologia de trabalho integradora que oferece resistência a práticas fragmentadas e, certamente, isso tem contribuído para uma melhor compreensão dos cenários indicados pelos resultados dos estudos. Essa interação constitui uma alavanca na promoção do desenvolvimento da SAMAM e na superação de obstáculos nos próximos 25 anos de conquistas.

\section{AGRADECIMENTOS}

Aos servidores, colaboradores, bolsistas e estudantes que contribuíram e que contribuem para a permanente construção do que é a SAMAM/IEC. Aos colegas de outras instituições, pelo compartilhamento de experiências no desenvolvimento dos projetos em colaboração. A todas as instituições parceiras ao longo da trajetória da SAMAM (para citar algumas IESC/UFRJ, CETEM/MCTIC, DNPM/MME, UFPA, JICA/NIMD/IML, Secretarias Estaduais e Municipais de Saúde e de Meio Ambiente nas áreas pesquisadas) pela colaboração. Aos órgãos de financiamento nacionais ( $M S, C N P q$, Fapespa, Ministério Público) e internacionais (JICA, União Europeia, UNIDO), por todo o apoio recebido na realização das pesquisas. $E$, especialmente, às comunidades e pessoas participantes das pesquisas e atividades desenvolvidas pela SAMAM, pela receptividade e credibilidade na seriedade do trabalho e no compromisso com a saúde pública e ambiental.

\section{REFERÊNCIAS}

1 Mnif W, Hassine AlH, Bouaziz A, Bartegi A, Thomas $\mathrm{O}$, Roig B. Effect of endocrine disruptor pesticides: a review. Int J Environ Res Public Health. 2011 Jun;8(6):2265-303.

2 Evangelou $E$, Ntritsos G, Chondrogiorgi M, Kavvoura FK, Hernández AF, Ntzani EE, et al. Exposure to pesticides and diabetes: a systematic review and meta-analysis. Environ Int. 2016 May;91:60-8.

3 Sekhotha MM, Monyeki KD, Sibuyi ME. Exposure to agrochemicals and cardiovascular disease: a review. Int J Environ Res Public Health. 2016 Feb; 13(2):229.

4 Carson R. Primavera silenciosa. 2. ed. Polilo R, tradutor. São Paulo: Melhoramentos; 1969. 305 p.
5 Moura RM. Rachel Carson e os agrotóxicos 45 anos após Primavera Silenciosa. An Acad Pernamb Cienc Agron. 2009;5-6:44-52.

6 Conferência das Nações Unidas sobre o Meio Ambiente e Desenvolvimento: de acordo com a Resolução $n^{\circ}$ 44/228 da Assembléia Geral da $\mathrm{ONU}$, de 22-12-89, estabelece uma abordagem equilibrada e integrada das questões relativas a meio ambiente e desenvolvimento: a Agenda 21. In: Conferência das Nações Unidas sobre o Meio Ambiente e Desenvolvimento; 1992 jun 3-14; Rio de Janeiro. Brasília: Câmara dos Deputados, Coordenação de Publicações. 1995. 472 p. (Série ação parlamentar; no. 56).

7 United Nations Environment Programme. Minamata convention on mercury. Nairobi: UNEP; 2013. $62 \mathrm{p}$. 
8 Rodrigues RM, Mascarenhas AFS, Ichihara AH, Souza TMC, Bidone ED, Bellia V, et al. Estudo dos impactos ambientais decorrentes do extrativismo mineral e polvição mercurial no Tapajós: pré-diagnóstico. Rio de Janeiro: CETEM/MCT; 1994. 220 p. (Série tecnologia mineral; no. 4).

9 Silva AP. Projeto Itaituba: programa de desenvolvimento de tecnologia ambiental. Rio de Janeiro: CETEM/MCT, 1997. 66 p. (Série tecnologia ambiental; no. 18).

10 Santos EO, Loureiro ECB, Jesus IM, Brabo E, Silva RSU, Soares MCP, et al. Diagnóstico das condições de saúde de uma comunidade garimpeira na região do rio Tapajós, Itaituba, Pará, Brasil, 1992. Cad Saude Publica. 1995 abr-jun; 11 (2):212-25.

11 Cleary D, Thornton I, Brown N, Kazantzis G, Delves T, Worthington S. Mercury in Brazil. Nature. 1994 Jan;369:613-4.

12 Uryu Y, Malm O, Thornton I, Payne I, Cleary D. Mercury contamination of fish and its implications for other wildlife of the Tapajós basin, Brazilian Amazon. Conserv Biol. 2001 Apr;15(2):438-46.

13 Grandiean P, White RF, Nielsen A, Cleary D, Santos ECO. Methylmercury neurotoxicity in Amazonian children downstream from gold mining. Environ Health Perspect. 1999 Jul;107(7):587-91.

14 Santos ECO, Jesus IM, Brabo ES, Loureiro ECB, Mascarenhas AFS, Weirich J, et al. Mercury exposure in riverside Amazon communities in Pará, Brazil. Environ Res. 2000 Oct;84(2):100-7.

15 Santos ECO, Câmara VM, Jesus IM, Brabo ES, Loureiro ECB, Mascarenhas AFS, et al. A contribution to the establishment of reference values for total mercury levels in hair and fish in Amazonia. Environ Res. 2002 Sep;90(1):6-11.

16 Jesus IM, Santos ECO, Brabo ES, Loureiro ECB, Câmara VM, Mascarenhas AFS, et al. Exposure to elemental mercury in urban workers and gold miners from the Tapajós region, Pará, Brazil. Bull Environ Contam Toxicol. 2001 Aug;67(3):317-23.

17 Brabo ES, Angélica RS, Silva AP, Faial KRF, Mascarenhas AFS, Santos ECO, et al. Assessment of mercury levels in soils, waters, bottom sediments and fishes of Acre State in Brazilian Amazon. Water Air Soil Pollut. 2003 Jul;147(1):61-77.

18 Santos ECO, Jesus IM, Brabo ES, Câmara VM, Loureiro ECB, Mascarenhas AF, et al. Exposure to mercury in the urban population of Rio Branco city, State of Acre, Brazil. Bull Environ Contam Toxicol. 2002 Sep;69(3):314-9.

19 Santos ECO, Jesus IM, Brabo ES, Fayal KF, Sá Filho GC, Lima MO, et al. Exposição ao mercúrio e ao arsênio em Estados da Amazônia: síntese dos estudos do Instituto Evandro Chagas/FUNASA. Rev Bras Epidemiol. 2003 jun;6(2):171-85.
20 Santos EO, Jesus IM, Câmara VM, Brabo ES, Jesus MI, Fayal KF, et al. Correlation between blood mercury levels in mothers and newborns in Itaituba, Pará State, Brazil. Cad Saude Publica. 2007;23 Suppl 4:S622-9.

21 Dutra MDS, Jesus IM, Santos ECO, Lima MO, Medeiros RLF, Cavadas $M$, et al. Longitudinal assessment of mercury exposure in schoolchildren in an urban area of the Brazilian Amazon. Cad Saude Publica. 2012 Aug;28(8):1539-45.

22 Castilhos Z, Rodrigues-Filho S, Cesar R, Rodrigues AP, Villas-Bôas R, Jesus l, et al. Human exposure and risk assessment associated with mercury contamination in artisanal gold mining areas in the Brazilian Amazon. Environ Sci Pollut Res Int. 2015 Aug;22(15): $11255-64$.

23 Carneiro BS, Faial KCF, Morais LLCS, Vale ER, Santos DSAS, Pinheiro SC, et al. Relatório técnico referente aos impactos ambientais nas águas superficiais ocasionados pelo naufrágio de um navio de carga viva ocorrido no porto de Vila do Conde - Barcarena/Pará. 2015. 74 p. Localizado em: Seção de Meio Ambiente, Instituto Evandro Chagas/SVS-MS, Belém, PA.

24 Santos EO, Sá GC, Jesus IM, Brabo ES, Câmara VM, Lima MO, et al. Mercúrio no rio Negro, Amazonas, Brasil: estudo preliminar de indicadores de exposição no pescado e em populações humanas. Cad Saude Coletiva. 2005 jan-mar;13(1):225-36.

25 Costa ML, Rego JAR, Brabo ES, Santos OC, Jesus IM, Almeida HDF, et al. $\bigcirc$ mercúrio em praias cultivadas da bacia do Juruá no estado do Acre. Geochem Bras. 2006;20(2): 148-57.

26 World Health Organization. United Nations Environmental Programme. Methylmercury. International Programme on Chemical Safety. Geneva: WHO; 1990. (Environmental health criteria; 101).

27 Marinho JS, Lima MO, Santos ECO, Jesus $\mathrm{IM}$, Pinheiro $\mathrm{MCN}$, Alves $\mathrm{CN}$, et al. Mercury speciation in hair of children in three communities of the Amazon, Brazil. Biomed Res Int. 2014; 2014:945963.

28 Dutra MDS, Cavadas M, Jesus IM, Santos EO, Silva EA, Câmara VM. Hearing thresholds in children exposed to mercury in the prenatal period. J Soc Bras Fonoaudiol. 2012;24(4):322-6.

29 Dutra MDS, Cavadas M, Jesus IM, Santos EO, Câmara VM. Effects of prenatal exposure to methylmercury in children auditory processing. Cad Saude Coletiva. 2016 Jan-Mar;24(1):70-6.

30 Torres JPM, Pfeiffer WC, Markowitz S, Pause R, Malm $O$, Japenga J. Dichlorodiphenyltrichloroethane in soil, river sediment, and fish in the Amazon in Brazil. Environ Res. 2002 Feb;88(2):134-9. 
31 Mendes RA, Lopes ASC, Souza LC, Lima MO, Santos LS. DDT concentration in fish from the Tapajos River in the Amazon region, Brazil. Chemosphere. 2016 Jun;153:340-5.

32 Mendes RA, Jesus IM, Santos ECO, Faial KF, Lima $\mathrm{MO}$, Carneiro BS. Níveis séricos de DDT total de trabalhadores expostos no programa de controle da malária no estado do Pará, Brasil. Cad Saude Coletiva. 2007 out-dez; 15(4):559-68.

33 Carneiro FF, organizador. Dossiê ABRASCO: um alerta sobre os impactos dos agrotóxicos na saúde. São Paulo: Expressão Popular; 2015. 624 p.

34 Morais LLC, Garza DR, Loureiro ECB, Vale ER, Santos DSAS, Corrêa VC, et al. Population and genetic study of Vibrio cholerae from the Amazon environment confirms that the WASA-1 prophage is the main marker of the epidemic strain that circulated in the region. PLoS One. 2013 Nov;8(11):81372.

35 Garza DR, Thompson CC, Loureiro ECB, Dutilh BE, Inada DT, Sousa Junior EC, et al. Genomewide study of the defective sucrose fermenter strain of Vibrio cholerae from the Latin American cholera epidemic. PLoS One. 2012 May;7(5):e37283.

36 Morais LLCS, Garza DR, Loureiro ECB, Nunes KNB, Vellasco RS, Silva CP, et al. Complete genome sequence of a sucrose-nonfermenting epidemic strain of Vibrio cholerae $\mathrm{O} 1$ from Brazil. J Bacteriol. 2012 May; 194(10):2772.
37 Pérez Chaparro PJ, McCulloch JA, Cerdeira LT, Al-Dilaimi A, Sá LLC, Oliveira R, et al. Whole genome sequencing of environmental Vibrio cholerae $\mathrm{O} 1$ from 10 nanograms of DNA using short reads. J Microbiol Methods. 2011 Nov;87(2): 208-12.

38 Teixeira DM, Hernandez JM, Silva LD, Oliveira DS, Spada PKP, Gurião TCM, et al. Occurrence of norovirus GIV in environmental water samples from Belém city, Amazon region, Brazil. Food Environ Virol. 2016 Mar;8(1):101-4.

39 Sá LLC, Vieira JMS, Mendes RA, Pinheiro SCC, Vale ER, Alves FAS, et al. Ocorrência de uma floração de cianobactérias tóxicas na margem direita do rio Tapajós, no Município de Santarém (Pará, Brasil).Rev Pan-Amaz Saude. 2010 mar; 1(1): 159-66.

40 Costa BNS, Pinheiro SCC, Lima MO, Amado LL. Microzooplankton as an indicator of environmental quality at an industrial complex in the Brazilian Amazon. Ecol Indicators. $2016 \mathrm{Jul}$; 66:220-9.

41 Ministry of the Environment (JP). Mercury analysis manual. Tokyo: Ministry of the Environment; 2004. $106 \mathrm{p}$. 